\title{
Appraisal patterns as predictors of emotional expressions and shares on political social networking sites
}

\author{
Thomas Zerback*, University of Zurich, Department of Communication and Media Research IKMZ, \\ Switzerland \\ Dominique S. Wirz, University of Fribourg, Department of Communication and Media Research \\ DCM, Switzerland \\ ${ }^{*}$ Corresponding author: t.zerback@ikmz.uzh.ch
}

\begin{abstract}
Emotions are considered important drivers of the diffusion of messages on social networking sites. Therefore, emotion-eliciting political communication yields the potential to reach broad audiences and to influence citizens' attitudes and behavior. In this study, we investigate message characteristics that potentially trigger emotional reactions on part of the users of political social networking pages and test if this fosters the diffusion of political content in the network. Based on appraisal theory, we employ a manual coding scheme to identify appraisal dimensions in political parties' Facebook posts that should trigger sadness or anger. We subsequently combine the manual codings with information of the users' reactions to the respective posts, which we gathered using an automated content analysis. More specifically, we determine (1) if posts that include sadness or anger appraisals are associated with the corresponding emotional reactions in the form of emojis and (2) if these posts are shared more often.
\end{abstract}

Keywords

appraisal emotions, affect, social media, shares, social networking sites, automatic content analysis, political communication

\section{Introduction}

For a long time, political communication research has largely neglected the role of emotions, mostly because they seem to contradict the image of an informed citizen guided by rational considerations (Marcus, 2000; Redlawsk, 2006). This began to change about two decades ago, when scholars started to question the notion of affect-free politics and found instead that emotions play a critical role throughout the communication process.

Most importantly, emotions or emotionalized content are a regular and salient feature of mediated political messages and the strategic communication efforts of political actors (e.g., Brader, 2006; Cho et al., 2003; Engesser, Fawzi, \& Larsson, 2017) and therefore frequently encountered by citizens. The exposure to such emotionalized political messages can lead to emotional reactions on the part of the audience (e.g., Chang, 2001; Lecheler, Schuck, \& Vreese,
2013; Wirz, 2018), with important further implications. First, communication and linguistic scholars have emphasized that emotional states affect the processing of political information (Plantin, 2004) and the formation of political attitudes (Kühne, 2012; Nabi, 2002), by serving as facilitators of argumentation and even as arguments themselves (Micheli, 2010). Second, specific discrete emotions - such as anger or sadness - inhere a strong motivational component and therefore can foster or inhibit political behaviors (Brader \& Marcus, 2013), such as political participation (Valentino, Brader, Groenendyk, Gregorowicz, \& Hutchings, 2011; Weber, 2012) and information seeking (Valentino, Hutchings, Banks, \& Davis, 2008).

With the advent of social networking sites (SNS), emotions have gained new impetus in the field of political communication. Not only do political actors use them as a strategic means in their online communication (Engesser et al., 2017), but 
also because citizens express and spread emotionalized content and reactions on the respective platforms (Eberl, Tolochko, Jost, Heidenreich, \& Boomgaarden, 2020; Stieglitz \& Dang-Xuan, 2014). Despite this recent interest in the role of emotions in the online world, we still know very little about (1) the prevalence of emotionalized content on political SNS, (2) how specific content triggers emotional reactions, and (3) how emotional reactions relate to other online behaviors, particularly sharing political content with others. These are the main questions we attempt to answer in the current paper.

To do so, we look at a widely used form of emotional expressions on SNS, the socalled emojis. Emojis are graphical representations of facial expressions, gestures, persons, objects, activities, or ideas that users of SNS can employ as a communicative means to express themselves (Tian, Galery, Dulcinati, Molimpakis, \& Sun, 2017). On Facebook, e. g., users can choose between six emojis ("Like", "Love", "Haha", "Wow", "Sad", and "Angry") to make their opinions and emotional states visible to others. We attempt to extend the existing body of research by identifying message-inherent factors that can explain the type and intensity of such emoji reactions to political messages. Our paper proceeds in four steps: First, we give a short overview on the literature on emoji use on SNS. After that, we use cognitive appraisal theory and the concept of intergroup emotions to identify message characteristics that potentially trigger emotional reactions. Because of their relevance as motivators of political action, we concentrate particularly on anger and sadness. Finally, we present the results of a quantitative content analysis we used to collect data on the emotion-eliciting message features of political posts and the number of emoji reactions and shares associated to them. The contribution of this study is thus two-fold: On the one hand, we show that appraisal theory can be applied to predict user reactions to political posts on SNS. On the other hand, we examine if emotion-eliciting message features influence how often a post is shared, and how shares depend on specific discrete emotions.

\section{Emojis as emotional expressions on SNS}

The term "emoji" denotes a graphic representation of facial expressions, gestures, persons, objects, activities, or ideas (Tian et al., 2017). In contrast to "emoticons", emojis do not consist of simple ASCII character sequences, e.g., “;-)”, but take the form of actual icons. Emojis were developed in Japan in 1999 to facilitate computer-mediated communication (CMC) and from there quickly spread worldwide to become a popular communicative feature in text messengers and on social networking sites (SNS) (Novak, Smailović, Sluban, \& Mozetič, 2015). On Twitter e.g., 4 to $13 \%$ of all messages (Novak et al., 2015; Pavalanathan \& Eisenstein, 2015) contain at least one emoji and according to a (non-representative) study examining the messages of two million U.S. Facebook users, $24 \%$ of all posts included an emoji, with $89.9 \%$ of the users including them at least once in their messages (Oleszkiewicz et al., 2017).

Compared to the use of emojis as elements within messages on SNS, far less is known about their function as possible reactions to previous messages. This seems surprising, since all large SNS provide predefined emojis that users can click on as a response to preceding posts. Instagram and Twitter e.g., offer a heartshaped emoji ("like"). Facebook also provides a "like"-button, but introduced five additional reactions in 2016, termed "love" (heart), "angry" (angry facial expression), "sad" (sad facial expression), "haha" (laughing facial expression), and "wow" (surprised facial expression), which since then became frequently used features as well. Tian et al. (2017) e.g., examined the Facebook sites of 15 media outlets in four different countries (US, UK, France, and Germany) and detected 57 million emoji reactions to the 21,000 posts analyzed in their study. This equals an average of 2,700 reactions per post. The most prominent 
reaction was "like" (78.9\%), followed by "love" (5.5\%), "angry" (5.4\%), "sad" (4.0\%), "haha" (3.7\%), and "wow" (2.5\%) with only marginal country-specific differences. Similarly, a study by the Pew Research Center shows that emoji reactions are also frequently used in the political realm (Hughes, 2018). Analyzing all Facebook posts by members of the U.S. Congress between February 2016 and July 2017, the authors observed 47.1 million emoji reactions (41.6\% "love", $37.4 \%$ "angry", $13.4 \%$ "sad", $4.7 \%$ "wow", $3.0 \%$ "haha"). Moreover, the distribution of users' reactions considerably varied over time: In the runup to the 2016 Presidential Election, the dominant response was "love" followed by anger, whereas after Election Day anger reactions increased considerably, eventually exceeding those of love after the inauguration. The study also provides some first hints on possible causes for users' "angry" reactions: In cases where the messages expressed opposition toward another political actor (e.g., a party or politician), $13 \%$ received angry reactions, compared to only $3 \%$ in cases without confrontational elements. A recent study by Eberl et al. (2020) demonstrates that "love" and "angry" reactions may also vary considerably between political parties. During the campaign for the Austrian parliamentary election in 2017, "angry" reactions made up $72 \%$ of all emoji reactions to posts by the Freedom Party (FPÖ), but only 15\% for the Social Democrats (SPÖ). "Love" on the other hand was a frequent reaction to the SPÖ's posts (50\%), but not to posts by the FPÖ (6\%). The empirically observed variance in emoji reactions to political messages calls for a deeper examination of their causes.

Although their name might suggest it, emojis do not necessarily express an emotion. ${ }^{1}$ In fact, most of them do not even depict emotional expressions, but other concepts, like activities (e.g., dancing), objects (e.g., beer mugs), or gestures (e.g.,

1 In fact, the term's resemblance to "emotion" is merely coincidental, since it is a combination of the Japanese words "e" (picture) and "moji" (character). victory sign) (Tian et al., 2017). Also, even emojis showing facial expressions can have non-emotional meanings, like e.g., a smiley with the tongue sticking out or a winking emoji used to mark a non-serious comment (Dresner \& Herring, 2010). To determine the meaning of different emojis, researchers have asked users to interpret them (Miller et al., 2016) or analyzed the textual context in which they appear (Novak et al., 2015). These studies show that some emojis have more ambiguous meanings than others. Particularly, different variants of sad faces with tears (Miller et al., 2016) and angry faces (Jaeger \& Ares, 2017) are among the less ambiguous emojis and strongly associated to sadness and anger as the respective discrete emotions. Hence "angry" and "sad" emojis are more likely to represent actual emotional expressions in response to a message, whereas others have non-emotional or less distinct emotional meanings. Therefore, we focus on "angry" and "sad" emojis in the current study. These reactions are not as ubiquitous as "like" or "love" reactions, and not as seldom as "wow" or "haha"; it seems that they represent adequate reactions in specific situations. In addition, anger and sadness are considered important drivers of political action. Anger e.g., is known to foster political action such as different forms of political participation (Brader \& Marcus, 2013), whereas sadness can exert a de-activating effect (Weber, 2012). Consequently, both emotions can be strategically employed by political actors to influence people's political activities.

In the following, we will take a closer look at how emotional reactions can be triggered by previous messages. We will (1) identify specific message characteristics that evoke certain discrete emotions and (2) explain why we can expect different individuals within a certain group to react similarly to these characteristics.

\section{Emotions as responses to messages on SNS}

The majority of emotions a person experiences are triggered by first-hand face- 
to-face contacts, and take place within established social relationships like the family, among friends, or in the workplace (Scherer, Wallbott, \& Summerfield, 2010). However, it is uncontested that emotional reactions can also result from contacts with media content and most of us probably have already experienced such media induced emotions, e.g., while watching a sad movie. In fact, Scherer et al. (2010) as well as Scherer and Tannenbaum (1986) estimate that $5 \%$ to $20 \%$ of all emotional episodes can be traced back to media use. Given the significance of media as a source for emotions, it is relevant to ask how exactly mediated messages can trigger emotional responses.

Previous studies have identified several message characteristics that motivate user reactions on SNS. However, most of them focus on reactions such as likes, shares, and comments (e.g., Bene, 2017; Blassnig, Ernst, Engesser, \& Esser, 2020; Blassnig \& Wirz, 2019; Bobba, 2019; Dang-Xuan, Stieglitz, Wladarsch, \& Neuberger, 2013; Heiss, Schmuck, \& Matthes, 2019; Keller \& Kleinen-von Königslöw, 2018), while less is known about factors triggering emoji reactions. An exception is a recent study by Eberl et al. (2020), demonstrating that posts with negative sentiment (i.e., containing more keywords with negative than positive valence) increase the number of angry reactions, while posts with positive sentiment increase the number of love reactions. This valence-based approach may however not explain how posts on SNS elicit different negative emotions, i.e., why some posts receive more "angry" and others more "sad" reactions. Appraisal theory is a promising way to predict different discrete emotions as reactions to messages.

\section{The role of cognitive appraisals in the elicitation of discrete emotions}

According to Scherer (2005, p. 697), an emotion is "an episode of interrelated, synchronized changes in the states of all or most of the five organismic subsystems in response to the evaluation of an exter- nal or internal stimulus event as relevant to major concerns of the organism." The five components Scherer refers to in his definition are (1) the cognitive component (appraisals), (2) the neurophysiological component (bodily symptoms), (3) the motivational component (action tendencies), (4) the motor expression component (facial and vocal expression), and (5) the subjective feeling component (emotional experiences). For example, anger occurs when a person perceives a situation as threatening and as intentionally caused by another person (cognitive appraisal). In such a situation, the person will experience physiological arousal indicated e.g., by an increased heart rate (bodily symptoms), their eyebrows will lower and slant inward (motor expression) and they will prepare to counter the perpetrator or remove the threat (motivation). Moreover, this person will also be able to express how the emotion "feels" (subjective experience). In the context of the study at hand, appraisal processes play a key role, because they are considered an important mechanism of how media messages can elicit emotions on the part of the audience (Gross \& D'Ambrosio, 2004). ${ }^{2}$

Appraisal theories of emotion elicitation rely on the notion that discrete emotional responses (like e.g., anger, fear, joy, or sadness) are the result of individual appraisals of situations or events that are important or relevant to a person (Scherer, 1993). Various appraisal approaches have been developed (e.g., Frijda, 1986; Lazarus, 1991; Scherer, 2001; C. A. Smith \& Ellsworth, 1985) showing a remarkable overlap regarding the central cognitive assessments that are assumed to influence the type and intensity of an emotional response to a given stimulus (Scherer, 1993). In the case of anger and sadness, these mutual appraisals are goal relevance, goal congruence, cause, responsibility, coping potential, and future expectations (see

2 There are other ways how the media can induce emotions, particularly emotional contagion and empathetic responses. However, in the case of political messages these mechanisms play a less important role than cognitive appraisals (see Scherer, 1998). 
e.g., Nerb \& Spada, 2001). In the following, we will focus on these appraisals and their combinations to explain the emergence of anger and sadness in response to political messages.

Goal relevance. A situation or event (e.g., a message) is relevant for the individual if it affects its central goals, motives, or concerns (Frijda, 1986). Relevance varies according to the position of the goal within one's personal goal hierarchy and / or with the number of goals affected (Scherer, 2001). For a student e.g., a message indicating that his university is planning to raise tuition fees should be of higher relevance compared to a message stating that another university is raising fees. The assessment of goal relevance is a decisive step in the appraisal process, because emotions are expected to occur only if the individual considers the situation relevant (Scherer, 2001). The more relevant the situation or event, the more intense the emotional reaction will be.

Goal congruence. Relevant events or situations can contribute to the achievement of personal goals, but also work against them. To stick to the above example, a raise of the universities tuition fees would be considered goal incongruent, because it may endanger the student's financial well-being or even the possibility to continue his studies, whereas a reduction of fees would be considered an improvement in this regard. The assessment of goal congruence determines whether the situation elicits positive or negative emotions. Appraisal theory predicts that goal incongruence results in negative emotions (e.g., sadness, anger, fear) whereas goal-congruent situations trigger a positive response (e.g., joy, pride) (Lazarus, 1991, pp. 217-296).

Causes and personal responsibility. When assessing a relevant situation, people usually tend to determine its cause or discern the agent responsible for its occurrence. Possible causes can be internal or external. Internal causes are located within the individuals assessing the situation, e.g., their abilities, character traits, or decisions. External causes, on the other hand, can either be other persons (e.g., their abilities, character traits, or decisions), or situational conditions (e.g., weather conditions). Closely related to the identification of a cause or agent for a given situation is the attribution of responsibility. In cases where solely situational conditions are identified as the cause of an event, an attribution of personal responsibility is not possible. However, when a person is identified as the agent, perceived personal responsibility for the situation can vary considerably. Individuals can blame themselves or others for a certain situation, because it was under their control and / or they willingly produced the respective outcome. On the other hand, perceived personal responsibility can be low or absent in cases of little control and / or intentions to produce a certain outcome. Depending on the congruence of the situation with one's personal goals, the attribution of causes and personal responsibility specific emotional responses will occur. For example, goal incongruent situations that are perceived to be caused by others who are held responsible for the situation should lead to anger (Frijda, 1986, p. 198), whereas situations with no personal responsibility should lead to sadness (e.g., Kühne \& Schemer, 2015; Nerb \& Spada, 2001). Goal congruent situations should always lead to positive emotions like joy or happiness, regardless of who or what is held responsible. However, if one attributes a positive situation to one's own personality and intent, pride should be the resulting emotion (Lazarus, 2001).

Coping potential. When someone is confronted with a goal-incongruent event (e.g., a thread), he or she will also tend to assess if there are ways to cope with the situation. Coping abilities depend especially on the perceived control over the situation and the power to exert this control. For example, if the student in our example sees no possibility to deal with the increased tuition fees, he will most likely experience sadness or even despair. If he recognizes a way out, e.g., by asking a wealthy relative for financial support, hope will evolve. The perception to be able to cope with a goal incongruent situation is also a characteristic of situations that evoke anger. Anger 
Table 1: Appraisal patterns and predicted emotional responses

\begin{tabular}{l|l|l}
\hline Appraisal & Anger / Rage & Sadness / Dejection \\
\hline Goal relevance & medium - high & High \\
Goal congruence & obstruct & obstruct \\
Cause / Agent & another person & Open \\
Responsibility & high & none - low \\
Coping potential & high & very low \\
Core relational theme & A demeaning offense against me and mine & Having experienced an irrevocable loss \\
\hline
\end{tabular}

Note: Based on Scherer (2001, pp. 114-115) and Lazarus (2001, p. 64) and adapted for the study.

prepares the organism for action, i.e., to counter the source of the anger (Carver \& Harmon-Jones, 2009). Therefore, some authors see perceived control over a situation as a necessary condition for anger to occur (Lerner \& Keltner, 2001). Although anger and sadness differ strongly with regard to perceived coping potential, both emotions are associated with an approach tendency; sad as well as angry individuals will dwell on the emotion-eliciting situation in order to find relief (Nabi, 1999).

Appraisal theory states that emotional responses result from specific combinations or configurations of single appraisals. These combinations are depicted in Table 1 for the two emotions central to our study (anger and sadness). Both appraisal patterns can be further synthesized to a denser and abstract meaning, which Lazarus (2001, pp. 63-64) termed "core relational themes". Core relational themes (bottom row of Table 1) reflect the central gestalt of an emotion-eliciting situation or event. In the case of anger, it is described as "a demeaning offense against me and mine" and for sadness, it is "having experienced an irrevocable loss".

Our previous remarks indicate that appraisal processes are highly subjective in nature and strongly depend on individual assessments. Consequently, people's emotional reactions to the same situation can be quite different, depending on what they personally consider important respectively good or bad. A Democrat e.g., probably shows a less intensive and/or more positive emotional response to a negative event happening to the Republican Party (e.g., joy), compared to a Republican whose reaction would probably be more intense and negative (e.g., sadness or anger). At the same time, emotional reactions within a group of Democrats or Republicans should be more homogenous, because group members usually share more similar notions of what is good / bad or relevant/irrelevant. In the following paragraph, we will therefore have a closer look on how group membership influences the formation of discrete emotions.

\section{Intergroup emotions}

Appraisal theory puts a strong focus on individual assessments of a specific situation or event. However, mediated messages differ in two important ways from this premise: First, a person encountering a message is usually not part of the situation depicted, but experiences it in an indirect and virtual way. ${ }^{3}$ Second, in many cases, the situations described in mediated messages (e.g., parliamentary debate) will not affect the person as an individual, but rather as part of a collective like, e.g., a group. Given this discrepancy, one has to justify why under such premises, appraisal theory is still a suitable approach to explain the emergence of emotions on the individual level.

The concept of "intergroup emotions" or "group-based emotions" (Mackie \& Smith, 2015, pp. 263-264) offers a theoretical link between the individual level processes described by appraisal theory and

3 An exception from this notion is Kepplinger's (2007) theory of reciprocal effects. The approach explains how the media affect subjects of media coverage (e.g., politicians). 
the group level. Group-based emotions are felt because of group membership and rely on processes of self-categorization and group identification (Mackie \& Smith, 2015, p. 263). For group-based emotions to occur, the group itself is neither required to be present, nor has the individual itself to be part of the emotion-eliciting situation (Niedenthal \& Brauer, 2012, p. 269). In addition, research has shown that especially political group affiliations promote the emergence of group-based emotions (E. R. Smith, Seger, \& Mackie, 2007).

Scholars of group-based emotions have integrated appraisal theory in their frameworks to explain emotions as a result of group membership. Very similar to the original psychological studies, they assume that specific combinations of appraisals in a given situation lead to specific emotional responses (Mackie \& Smith, 2015). The difference between the traditional and the group-based approaches is that the latter rely on intergroup rather than individual appraisals. Self-categorization leads individuals to see the world through the eyes of their in-group and consequently, the appraisals mentioned before are carried out from a group perspective as well. For example, when reading a political party's message on Facebook describing a certain event, a follower of that party might ask himself questions such as: Is the event relevant for my party? Does the event help or harm my party? Who is responsible for the situation? Can my party cope with the consequences? Depending on the answers - the group-based appraisals - emotional reactions like joy, anger, pride, guilt, or sadness can occur.

Research has shown that individuals as group members experience emotions on behalf of their group, even when they are not part of the respective events nor directly affected by them (see Mackie \& Smith, 2015 for an overview). Soccer fans for example - although not playing for their favorite team themselves - usually show strong emotional reactions, like joy, anger or sadness, if their favorite team wins or loses (Crisp, Heuston, Farr, \& Turner, 2007). Similarly, individuals can feel guilt or pride as a reaction to the actions taken by their group without being personally involved in the group's actions (Doosje, Branscombe, Spears, \& Manstead, 1998).

Based on both approaches (appraisal theory and intergroup emotions) we predict the following associations between message-inherent appraisal patterns and emotional expressions in the form of emojis:

H1: Facebook posts including an anger-specific appraisal pattern will receive a higher number of anger emoji reactions compared to those without such a pattern.

H2: Facebook posts including a sadness-specific appraisal pattern will receive a higher number of sad emoji reactions compared to those without such a pattern.

\section{Emotions and political action}

Several studies have linked media induced emotions to political attitudes or behavior (see Brader \& Marcus, 2013 for an overview). Thereby, anger and sadness have shown to have different effects (e.g., DeSteno, Petty, Rucker, Wegener, \& Braverman, 2004; Lerner \& Tiedens, 2006). Although both emotions go along with a tendency to approach the emotion-eliciting situation (Nabi, 1999), anger is associated with heuristic information processing, while sadness leads to more substantial processing (see Lerner \& Tiedens, 2006 for an overview). This is explained with the difference of perceived control that is associated with the two emotions. Angry people feel they are in control of the situation, engage in more risk-seeking behavior (Lerner \& Keltner, 2001) and have a lower need for accuracy. Sad people on the other hand exhibit a lower level of perceived control and therefore act more carefully. Anger and sadness also differ in their appraisal tendencies, or the emotional needs they induce, which results in different political preferences. Angry individuals look for punishment of the culprit and therefore are more favorable of putative 
measures, while sad individuals look for help to cope with the loss they or someone else experienced, are more favorable for preventive measures (DeSteno et al., 2004; Kühne \& Schemer, 2015) and tend to engage more in information seeking behavior (Brader \& Marcus, 2013). Hence, although both emotions are negative in valence and lead to some engagement with the emotion-eliciting event, they result in different information processing behavior as well as in different policy preferences and actions.

The emotional reactions individuals experience in response to a post on SNS may not only find expressions in emojis, they can also affect further actions such as sharing the message. Compared to liking (and other reactions), which represent low-threshold options for opinion expression, sharing a post is considered to be a result of higher elaboration (Porten-Cheé, Haßler, Jost, Eilders, \& Maurer, 2018). First, individuals are aware of the visibility of shared posts and the potential consequences of expressing their opinion in public, and second, they consider if content is relevant to their peers before sharing it. Porten-Cheé et al. (2018) therefore conclude that the more individuals are cognitively involved with the content of a post, the more likely they will share it. In line with these reflections, Dang-Xuan et al. (2013) found that emotional tweets are shared more frequently than non-emotional tweets, as emotions generate attention and foster cognitive involvement.

Following this line of argumentation and the different action tendencies triggered by anger and sadness, we could expect that content evoking sadness would be shared less often than content evoking anger, as anger reduces the need for accuracy, promotes risky behavior (Lerner \& Keltner, 2001) and mobilizes the individual to counter the cause of the anger (Brader \& Marcus, 2013). Another explanation for why emotional content is shared more frequently is provided by Berger and Milkman (2012), who identified emotional arousal as a driver for sharing content online. From this perspective, we could also expect that content evoking anger is shared more often than content evoking sadness, as anger is a high-arousal emotion, whereas sadness is a low-arousal emotion. Indeed, empirical evidence points into this direction; in their study, Berger and Milkman (2012) found that anger increased the frequency of sharing while sadness did not. This finding indicates that in the case of content evoking anger or sadness, emotional arousal is the better predictor for sharing than cognitive involvement. Based on these considerations we predict a positive relationship between anger and sharing political content on SNS:

H3: Anger-eliciting posts will be shared more frequently than posts that do not elicit anger.

In the case of sadness, theoretical predictions are less clear, because - as we have seen - sadness is associated with higher levels of cognitive elaboration, which should result in stronger action tendencies, but also with a lower arousal level, which inhibits subsequent actions. Therefore, we additionally pose the following research question:

RQ1: Is there an association between sadness-eliciting posts and the frequency of shares?

\section{Method}

To test our hypotheses, we analyzed the Facebook pages of the six largest German political parties (CDU, SPD, AfD, FDP, The Left, and The Green Party). From all posts published during our period of investigation $(N=4,160 ; 1$ January 2017 to 26 February 2018), a disproportionally stratified random sample of $N=600$ posts was drawn (Davern, 2008) by randomly selecting 100 posts from each party's overall corpus. In doing so, we ensured that less active parties on social media still entered the overall sample with a statistically sufficient amount of posts. It is important to note that while (non-weighted) disproportionate random samples do not provide valid point estimates regarding the whole 
population, they do so for the different strata - in our case the six parties. ${ }^{4}$

To gather post specific information, we employed a combination of automatic and manual quantitative content analysis. The automated part was completed by using "Facepager", a software tool that allows to retrieve publicly available information via Facebook's API (Jünger \& Keyling, 2017). For each post, we collected its date and time, the posting political party and most important - the number of users' "angry" and "sad" reactions as well as the total number of shares. The manual coding procedure was used to obtain information on the emotion eliciting content within each post, i.e., to assess the appraisal dimensions. We thus used automated coding for some variables, and manual coding for others, depending on which approach was most suitable to measure the given variable with high reliability and validity. For the manual coding, twenty-two human coders were randomly assigned an equal number of party postings and trained to secure reliable measures. Five of the coders did not take part in the reliability test and their codings were therefore removed from the final sample ${ }^{5}$ resulting in a total of $N=463$ posts as the basis for the following analyses. Intercoder reliability was determined based on 18 jointly coded posts using the Lotus coefficient (Fretwurst, 2015) with acceptable results ( $=.64$ to .78 ).

\subsection{Measurement of appraisals}

The coders analyzed each post and identified anger- and sadness-specific appraisal patterns. In a first step, they identified the main event of each post as indicated by the

4 In addition to this advantage, stratified random samples (proportional and disproportional) increase the efficiency of sample estimates in cases where the variables used to stratify the target population are related to the characteristic being studied (Davern, 2008). Since the number of emotional reactions and shares strongly depend on the type of party (due to the varying number of followers) this advantage especially applies to our case.

5 Since all coders were randomly assigned the posts, no systematic bias was expected from removing particular coders. headline. In cases where no headline was available, the main event was determined as the one taking up most of the post's text. After that, the coders separately went through the appraisal steps described above (goal relevance, goal congruence, causes and responsibility, coping potential) to identify anger- and sadness-specific appraisal patterns. As a result, each post was assigned only one emotional core theme. All coders were instructed to evaluate each post from the perspective of the partisans of the respective party. This instruction was given based on our earlier remarks on intergroup emotions, because we assumed that regular visitors of the political parties' sites would most likely be partisan followers or at least likeminded sympathizers holding relatively similar notions of what is good, bad, or relevant for the party (Klinger \& Svensson, 2014). This is a critical assumption, because a sufficiently high intragroup agreement regarding the assessment of an event's goal relevance and goal congruence is necessary to evoke similar group-wide emotions.

Goal relevance was coded on a fourpoint scale reaching from 1 (the situation described in the post has no relevance for the party) to 4 (high relevance for the party). To measure goal congruence, we employed a simple dichotomous category indicating if the situation described in the post was congruent (1) or incongruent (0) with the party's goals. We also assessed if the post mentioned a cause for the given situation and differentiated between four possible agents: the party itself or one of its members, another party or one of its members, another organization or one of its members, and external circumstances (e.g., the economy). For all possible causes, we then determined the degree of personal responsibility for the situation using a four-point scale reaching from 1 (the actor bears no responsibility for the situation) to 4 (the actor bears high responsibility for the situation). In cases where external circumstances were identified as the cause, personal responsibility was coded as absent. Finally, we coded the parties' coping potential to deal with the situation using a dichotomous category indicating if 
the (negative) situation can be reversed / improved (1) or not (0).

Following the theoretical configurations shown in Table 1, we used the appraisal codings above to construct two new dummy variables indicating the presence of an anger- or a sadness-specific core relational theme in a posting. An "anger core theme" was operationalized as a situation depicted as at least moderately relevant to the party, goal incongruent, identifying another party or organization as the cause of the situation and blaming it for it. However, there still had to be a possibility to cope with the situation. An example would be a post accusing the governing party of being responsible for high unemployment rates accompanied by the suggestion to vote for the opposition. Similarly, the "sadness core theme" was assigned to all posts mentioning situations that were coded at least moderately relevant to the party and goal incongruent. However, unlike in the case of anger, the cause of the situation described (regardless of its type) had to be free of responsibility. Finally, a sadness core theme required that there was no way for the party to reverse or improve the situation. An example for the latter case were death notices of politicians on the parties' Facebook pages. Sadness and anger themes were thus eventually coded to be either present (1) or absent (0) in a post based on the appraisal components.

\subsection{Control variables}

In addition to the effects of our independent variables, we also accounted for several control variables that can affect reactions and sharing. First, all posts were collected at the same date (26 February 2018), hence some had been online for more than a year, and others just for a few days. Since an earlier publication date may be associated with more reactions and shares, we included the number of days since publication. Second, the number and characteristics of followers of the investigated Facebook pages may influence the frequency of reactions to the posts (see also Table 2). The party pages (CDU, SPD, FDP, The Left, and The Green Party while AfD was the reference category) were thus included as dummy coded controls. Third, reactions may be more frequent when posts include visual elements such as a picture or video, therefore their presence was also controlled for. Finally, the general newsworthiness of posts is known to foster reactions in online settings (Weber, 2014); therefore, a news value index was constructed for each post by summing up all present news factors (i.e., prominence, sex, spatial proximity, consequence, surprise, conflict, humor, presence of political actors, and personal information about political actors, see Eilders, 2006). Next to this, we included some variables that might specifically influence the frequency of sharing a post: Some posts contained an explicit call to share, thus a dummy variable was introduced to control for this. Further, since sharing might also be influenced by positive emotions (Berger \& Milkman, 2012), we included the number of non-negative emoji reactions (i.e., "haha", "wow", "love") and the number of likes as control variable.

\section{Results}

Before we test our hypotheses, it is worthwhile to look at how frequently the two core relational themes on each party's Facebook page occurred. As can be seen in Table 2, the anger theme dominated and was found in $8.9 \%$ of all posts, whereas the sadness theme was less common and only present in $4.8 \%$ of the cases.

We can also observe significant partyspecific differences: Whereas the two currently governing political parties (CDU and SPD) make only marginal use of both core themes, the opposition shows significantly higher shares. This especially applies to the populist AfD, who also was the only party using both core themes almost equally often. All other opposition parties prioritized the anger over the sadness theme. These results coincide with the work of other scholars who claim emotionalization to be a central component of the populist communication style (Engesser et al., 2017). 
Table 2: $\quad$ Prevalence of anger and sadness core relational themes on political parties' Facebook pages

\begin{tabular}{l|ccccccc}
\hline & $\begin{array}{c}\text { CDU } \\
(\mathrm{n}=81)\end{array}$ & $\begin{array}{c}\text { SPD } \\
(\mathrm{n}=76)\end{array}$ & $\begin{array}{c}\text { AfD } \\
(\mathrm{n}=73)\end{array}$ & $\begin{array}{c}\text { FDP } \\
(\mathrm{n}=78)\end{array}$ & $\begin{array}{c}\text { The Left } \\
(\mathrm{n}=78)\end{array}$ & $\begin{array}{c}\text { The Green Party } \\
(\mathrm{n}=77)\end{array}$ & $\begin{array}{c}\text { All } \\
(\mathrm{N}=463)\end{array}$ \\
\hline Anger (\%) & 1.2 & 3.9 & 16.4 & 7.7 & 14.1 & 10.4 & 8.9 \\
Sadness (\%) & 1.2 & 1.3 & 13.7 & 3.8 & 5.1 & 3.9 & 4.8 \\
$\begin{array}{l}\text { Number } \\
\text { of fans* }\end{array}$ & 124293 & 121265 & 310407 & 56678 & 169109 & 132540 & 914292 \\
\hline
\end{tabular}

Note: *Number of Facebook fans at the beginning of the investigation period (January 1st 2017). Anger: $\chi^{2}(463)=16.31, p=.006$, sadness: $\chi^{2}(463)=17.40, p=.004$, total share: $\chi^{2}(463)=32.43, p=.000$.

We now turn to the main goal of our study and examine the relationship between the presence of anger and sadness core themes in the parties' posts, users' emoji reactions to them, and the resulting number of shares. Since our endogenous variables are counts and show a substantial level of over-dispersion, we employed a negative binomial regression model to determine the relationships between them (see Gardner, Mulvey, \& Shaw, 1995 for an overview of the method and its application for count data). The analyses were performed using SPSS 25. Results are displayed in Table 3 and 4; since negative binomial regression coefficients represent the log change of expected counts on the dependent variable and are thus not easy to be interpreted, the tables also show the exponential estimates, which represent the incident rate ratio (IRR). This value can be interpreted as a factor, with which the outcome is multiplied. Thus, values smaller than 1 represent a decrease and values higher than one an increase in the dependent variable.

$\mathrm{H} 1$ predicts that posts featuring an anger theme receive a higher number of angry emoji reactions than posts without such a theme. This assumption is supported by the data, $b=0.54, S E=0.17, p=<$ .001 . Similarly, as predicted by $\mathrm{H} 2$, posts reflecting a sadness theme led to a higher number of sad emoji reactions compared to posts without such a theme, $b=1.16$, $S E=0.23, p<.001$. The exponential coefficient reveals that the presence of an anger theme increases angry emojis by a factor of 1.71 , thus posts with an anger theme get $71 \%$ more angry emojis than posts without this theme. The presence of a sadness theme increases sad emojis by a factor of 3.19. However, the results also reveal that the sadness theme fosters angry emojis, and the anger theme also fosters sad emojis (see Table 3). While sad emojis are driven more strongly by the sadness compared to the anger theme, anger emojis are driven more strongly by the sadness theme, which is an unexpected result. The control variables further reveal that the presence of visual elements drives both types of emoji reactions, while news value only fosters sad emojis. Posts on the AfD page further generate a higher number of sad and angry reactions compared to posts on other party pages. ${ }^{6}$

H3 predicts that posts that elicited anger are also shared more often. This assumption can be tested in two ways. First, we can look at the effect of the presence of an anger theme on the number of shares (see Model 1). There is no significant effect of the anger theme on sharing, but there is one for the presence of a sadness theme, $b=0.57, S E=0.24, p=0.02$. Shares increase by $77 \%$ percent when a sadness theme is present in a post. A second way to test the hypothesis is to look at the relationship between the presence of angry emojis and number of shares (see Model 2). Here we see a small but significant effect, $b=0.001$,

6 Since emoji reactions seem to be driven particularly by the AfD, we conducted an additional analysis to see if the relationship between anger and sadness themes and the corresponding emoji reactions exists for posts of all parties. The analysis is reported in the online appendix of this paper. The results show that the phenomenon is enhanced for posts on the AfD page, but it also exists for the other parties' posts. 
Table 3: Model estimates (unstandardized negative binomial regression coefficients)

\begin{tabular}{l|rrrr|rrrr}
\hline & \multicolumn{4}{|c|}{ Angry emoji reactions } & \multicolumn{4}{c}{ Sad emoji reactions } \\
& $\mathrm{b}$ & $\mathrm{SE}$ & Exp(b) & $\mathrm{p}$ & $\mathrm{b}$ & $\mathrm{SE}$ & $\mathrm{Exp}(\mathrm{b})$ & $\mathrm{p}$ \\
\hline Constant & 6.79 & 0.22 & 884.96 & 0.00 & 4.82 & 0.23 & 123.85 & 0.00 \\
Anger theme & 0.54 & 0.17 & 1.71 & 0.00 & 0.38 & 0.18 & 1.46 & 0.03 \\
Sadness theme & 1.64 & 0.23 & 5.16 & 0.00 & 1.16 & 0.23 & 3.19 & 0.00 \\
Days since publication & -0.01 & 0.00 & 1.00 & 0.00 & 0.00 & 0.00 & 1.00 & 0.00 \\
Party: CDU & -3.32 & 0.17 & 0.04 & 0.00 & -3.38 & 0.18 & 0.03 & 0.00 \\
Party: SPD & -2.68 & 0.18 & 0.07 & 0.00 & -2.30 & 0.18 & 0.10 & 0.00 \\
Party: FDP & -4.25 & 0.17 & 0.01 & 0.00 & -3.41 & 0.18 & 0.03 & 0.00 \\
Party: The Left & -2.10 & 0.17 & 0.12 & 0.00 & -1.10 & 0.18 & 0.33 & 0.00 \\
Party: The Green Party & -3.29 & 0.17 & 0.04 & 0.00 & -1.21 & 0.17 & 0.30 & 0.00 \\
News value & 0.01 & 0.02 & 1.01 & 0.62 & -0.06 & 0.02 & 0.94 & 0.00 \\
Visual elements & 0.27 & 0.16 & 1.31 & 0.09 & 0.34 & 0.17 & 1.40 & 0.04 \\
\hline
\end{tabular}

Table 4: Effects of emotional expressions and emotion-eliciting themes on the number of shares (unstandardized negative binomial regression coefficients)

\begin{tabular}{|c|c|c|c|c|c|c|c|c|c|c|c|c|}
\hline \multirow[b]{3}{*}{ Constant } & \multicolumn{4}{|c|}{ Model 1} & \multicolumn{4}{|c|}{ Model 2} & \multicolumn{4}{|c|}{ Model 3} \\
\hline & \multirow{2}{*}{$\frac{b}{5.20}$} & \multirow{2}{*}{$\frac{\text { SE }}{0.25}$} & \multicolumn{2}{|c|}{$\operatorname{Exp}(b)$} & \multirow{2}{*}{$\frac{b}{4.30}$} & \multirow{2}{*}{$\frac{\text { SE }}{0.27}$} & \multicolumn{2}{|c|}{$\operatorname{Exp}(b)$} & \multirow{2}{*}{$\frac{b}{4.31}$} & \multirow{2}{*}{$\frac{\text { SE }}{0.27}$} & \multirow{2}{*}{$\frac{\operatorname{Exp}(b)}{74.33}$} & \multirow{2}{*}{$\frac{p}{0.00}$} \\
\hline & & & 180.67 & 0.00 & & & 73.78 & 0.00 & & & & \\
\hline Anger theme & 0.30 & 0.19 & 1.35 & 0.11 & & & & & 0.16 & 0.19 & 1.17 & 0.41 \\
\hline Sadness theme & 0.57 & 0.24 & 1.77 & 0.02 & & & & & 0.18 & 0.24 & 1.19 & 0.46 \\
\hline Angry emoji reactions & & & & & 0.001 & 0.00 & 1.001 & 0.00 & 0.001 & 0.00 & 1.001 & 0.00 \\
\hline Sad emoji reactions & & & & & 0.002 & 0.00 & 1.002 & 0.04 & 0.002 & 0.00 & 1.002 & 0.04 \\
\hline Days since publication & 0.00 & 0.00 & 1.00 & 0.55 & 0.00 & 0.00 & 1.00 & 0.38 & 0.00 & 0.00 & 1.00 & 0.41 \\
\hline Party: CDU & -1.11 & 0.19 & 0.33 & 0.00 & -0.41 & 0.21 & 0.66 & 0.05 & -0.41 & 0.21 & 0.67 & 0.05 \\
\hline Party: SPD & -0.67 & 0.19 & 0.51 & 0.00 & 0.04 & 0.20 & 1.04 & 0.86 & 0.04 & 0.20 & 1.04 & 0.83 \\
\hline Party: FDP & -1.50 & 0.19 & 0.22 & 0.00 & -0.74 & 0.21 & 0.48 & 0.00 & -0.74 & 0.21 & 0.48 & 0.00 \\
\hline Party: Left & -0.63 & 0.18 & 0.53 & 0.00 & 0.00 & 0.20 & 1.00 & 0.99 & -0.01 & 0.20 & 0.99 & 0.95 \\
\hline Party: Green & -0.91 & 0.20 & 0.40 & 0.00 & -0.05 & 0.24 & 0.95 & 0.84 & -0.06 & 0.24 & 0.94 & 0.79 \\
\hline News value & 0.02 & 0.02 & 1.03 & 0.18 & 0.03 & 0.02 & 1.03 & 0.06 & 0.03 & 0.02 & 1.03 & 0.09 \\
\hline Visual elements & 0.41 & 0.18 & 1.50 & 0.02 & 0.43 & 0.18 & 1.53 & 0.02 & 0.42 & 0.18 & 1.52 & 0.02 \\
\hline Call to share & 0.81 & 0.19 & 2.25 & 0.00 & 0.54 & 0.21 & 1.72 & 0.01 & 0.54 & 0.21 & 1.71 & 0.01 \\
\hline Likes & 0.00 & 0.00 & 1.00 & 0.00 & 0.00 & 0.00 & 1.00 & 0.00 & 0.00 & 0.00 & 1.00 & 0.00 \\
\hline \multirow[t]{2}{*}{$\begin{array}{l}\text { Positive emoji } \\
\text { reactions }\end{array}$} & 0.00 & 0.00 & 1.00 & 0.52 & 0.00 & 0.00 & 1.00 & 0.48 & 0.00 & 0.00 & 1.00 & 0.43 \\
\hline & \multicolumn{4}{|c|}{$\begin{array}{c}\text { AIC: } 5419.20 \\
\text { Log-likelihood: }-2695.60 \\
\text { Omnibus-Test: } 573.22^{* * *} \\
\text { (df }=13 \text { ) } \\
\mathrm{n}=408\end{array}$} & \multicolumn{4}{|c|}{$\begin{array}{c}\text { AIC: } 5376.49 \\
\text { Log-likelihood: }-2674.24 \\
\text { Omnibus-Test: } 615.93^{* * *} \\
\qquad \begin{array}{c}\text { (df }=13) \\
n=408\end{array}\end{array}$} & \multicolumn{4}{|c|}{$\begin{array}{c}\text { AIC: } 5379.36 \\
\text { Log-likelihood: }-2673.68 \\
\text { Omnibus-Test: } 617.06^{* * *} \\
\qquad \begin{array}{c}\text { (df }=15) \\
\mathrm{n}=408\end{array}\end{array}$} \\
\hline
\end{tabular}


$S E=0.00, p<.001$. For 100 additional angry emojis, the number of shares increases by $10 \%$. Again, there is also a significant effect for sad emojis on sharing, which suggests that for 100 additional sad emojis, the number of shares increases by $20 \%$. If both approaches are combined (see Model 3), the significant effect of the core relational theme disappears, while the effects of emoji reactions on the number of shares persist. Additionally, visual elements, a call to share the post, inherent news value and the number of likes have a positive effect on the number of shares. Posts on the pages of CDU and FDP were shared significantly less often than posts of the AfD (reference category), while no difference emerged between other parties and the AfD. H3 is thus partly supported, since there is a positive effect of angry emoji reactions and the number of shares. Regarding RQ1 we find that sadness emojis also have a positive effect on the numbers of shares.

\section{Discussion and conclusion}

The aim of this paper was to investigate whether political communication on Facebook triggers emotional reactions and influence the frequency of sharing a post. Based on functional theories of emotions, we expected that specific appraisal dimensions in Facebook posts elicit discrete emotions, such as anger or sadness, expressed by the respective emoji reaction to a post. In line with the appraisal tendency framework, we further expected that anger eliciting posts would be shared more often, while no clear theoretical prediction was possible for sadness eliciting posts. The results of our content analysis of the Facebook pages of German political parties were mostly supportive of these assumptions. Facebook posts exhibiting appraisal dimensions known to elicit anger triggered more angry emoji reactions than posts without these characteristics, while posts exhibiting sadness eliciting appraisals resulted in more sadness emoji reactions. In addition, the number of angry and sad emoji reactions were also pos- itively related to the number of shares. It is noteworthy that this relationship exists after controlling for the number of likes of the posts, which may indicate positive reactions as well as the general popularity of a post.

Unexpectedly, posts reflecting a sadness theme also triggered angry emoji reactions, even more so than they triggered sad reactions. Further, when not considering reactions to the post as a predictor for shares, the sadness theme has a stronger effect on sharing than the anger theme. We can conclude from this finding that sadness themed posts are shared more often, not only because they elicit sadness, but especially because they elicit anger. Anger and sadness are both caused by negative events; if someone can be held responsible for the event, then the resulting emotion should be anger, if nobody can be held responsible sadness should occur. The results suggest that even if a Facebook post does not blame someone for the situation, individuals might still perceive someone to be accountable and therefore react with anger rather than sadness. This points to a limitation of our content analysis with regard to the intersubjective coding of appraisal dimensions.

Unlike previous research (Berger \& Milkman, 2012), we also found a positive effect of sadness emojis on the number of shares (on top of the effect caused by angry emojis). It could be that media induced sadness triggers different motivational goals than sadness in response to real events; media induced sadness is most likely not caused by a personal loss, but by the loss of someone else, and in some cases, individuals might perceive that sharing a message can protect others (including themselves) from similar experiences. Thus, it might be that while individuals are not particularly motivated to share sad news stories in general (Berger \& Milkman, 2012), they might do so when they feel this could have a political impact. The relationship between sadness and sharing of media content and political posts should therefore be investigated more thoroughly in the future. 
The study of emotional reactions on social media is particularly interesting because these platforms have a high potential to elicit emotions due to their social component on the one hand, and because such emotional expressions may serve as indicators of an existing emotional norm within a certain group. Studies in the context of intergroup emotions have shown that when individuals become aware of emotional reactions within their group, they tend to converge toward this perceived emotional norm or prototype. This effect has been demonstrated for positive (happiness) and negative emotions (fear and anger) (Moons, Leonard, Mackie, \& Smith, 2009). Other researchers have already pointed out the potential importance of online popularity indicators (e.g., likes or shares) as cues to public opinion or other aspects of social reality (Porten-Cheé et al., 2018). Such perceptions might not only strengthen the in-group identity of group members, they might also provoke a chain of emotional reactions, which might lead to the spread of online emotions (e.g., in the course of so-called firestorms). Future research could therefore investigate the dynamics of emotional reactions on social networks in order to obtain more insights on emotional contagion on online platforms (see e.g., Stieglitz \& Dang-Xuan, 2014). Our results suggest that the group context does matter on Facebook; not only did the messages posted by the AfD exhibit more emotion eliciting characteristics than posts by other parties, the AfD followers were also more likely to use emotional reactions and to share posts in their network. Future research should therefore also consider characteristics of the communicator of political messages on social media, as well as those of the followers of a page.

All in all, this study has used an innovative approach to assess the emotion eliciting potential of social media posts by measuring appraisal components on the one hand, and by measuring users' emotional reactions to such posts relying on emoji reactions on the other hand. Our results suggest that both measures are useful, as the captured appraisal patterns triggered the corresponding emotional reactions. Further, the study has shown that anger and sadness eliciting posts are shared more often than other posts on Facebook. This may help to understand why negative news and hate speech spreads fast on social media, especially within certain groups. The results also suggest that political actors can reach a larger audience on social media using messages evoking negative emotions.

Of course, our study has also limitations. First, we cannot be sure if users express emotions they experience in response to a Facebook post by using emojis, and we also cannot be sure whether they use the "correct" emojis. For example, users who experience guilt or shame in response to a post may also use the sad emoji. In other words, the congruence between experienced emotions and emoji expressions is not always given. However, our results suggest that at least anger and sadness emojis are good indicators for the respective emotions, as they are triggered by the corresponding appraisal patterns. Second, we decided to assign only one emotional core theme to a post. Although this seemed to be an adequate procedure, since the parties' messages were rather brief ( $M=67.04$ words) and mostly focused on one event, it ignores the fact that a single post may deal with several events or with a single event that triggers more than one emotion. Cases where several emotions co-occur are also known as "emotion blends" (Scherer, 1998, p. 147). As a subset of emotion blends, "mixed emotions" specifically refer to the co-occurrence of emotions that are of opposite valence. A prominent example of mixed emotions are so-called "bittersweet events" that elicit joy and sadness (Larsen \& McGraw, 2014). Whereas some researchers assume that emotions of opposite valence are mutually exclusive and therefore cannot exist at the same time (e.g., Russell \& Carroll, 1999), others find support for the opposite. Larsen and McGraw (2014) e.g., provide evidence for mixed emotions after participants watched a film whose ending contained both a good and a bad event. While recent studies indicate that mixed 
emotions exist, not much is known about their behavioral consequences. However, studies in health communication suggest that mixed emotional appeals (e.g., fear appeals that also elicit hope), can increase a person's behavioral motivation compared to mere negative emotional appeals (Carrera, Muñoz, \& Caballero, 2010; Myrick \& Oliver, 2015). Third, in the current paper, we proposed and implemented a content-analytic way to measure the implicit emotionalization of text messages derived from appraisal theory. One restraint of this approach when analyzing large quantities of text like social media messages surely lies in the limited capacity of human coders. Although human coding offers various advantages, automated methods would be much more efficient in this regard. However, existing automated tools (like the Linguistic Inquiry and Word Count, LIWC or the NRC Emotion Lexicon) are dictionary-based and detect emotions by counting emotion-specific expressions (e.g., "angry" or "mad"). Our approach, on the other hand, focuses on the implicit emotionalization of a message, by analyzing the specific situation described in the text. Such a situation can be highly emotional without using any explicit emotional expressions. For example, a post can describe the situation in a refugee camp and completely lack explicit emotional expressions like "sad" or "grief". Nevertheless, it evokes sadness, because it contains information on the situation or conditions the refugees face (e.g., lack of food or shelter, diseases, or death). Although dictionary-based methods are well capable of detecting the general negative tone or valence of such a text by counting negatively connotated words (e.g., death), they fail to distinguish which specific negative emotion is transmitted (here: sadness or anger). Despite these restraints, we think dictionary-based methods inhere great potential for the analysis of implicit emotionalization, when they are supplemented by specific appraisal categories. These supplements e.g., could include the attribution of responsibility or future expectations that are addressed in the text. Similar to our operationalization, specific configurations of these categories could be used to determine situations that are likely to trigger specific discrete emotions. Finally, some of the variation in the use of emoji reactions to the posts may also be explained by variables we could not observe. For example, user-characteristics like e.g., gender or age have been shown to influence emoji use (e.g., Prada et al., 2018).

\section{Acknowledgement}

We especially thank the student participants in the seminar "Factors of success in political communication on social media" who conducted the coding during the summer term of 2018 at the Department of Media and Communication at the LudwigMaximilians-University, Munich.

\section{Supplementary Material}

Supplementary material for this article is available online in the format provided by the authors (unedited).

https://www.hope.uzh.ch/scoms/article/ view/j.scoms.2021.01.003

\section{References}

Bene, M. (2017). Go viral on the Facebook! Interactions between candidates and followers on Facebook during the Hungarian general election campaign of 2014. Information, Communication \& Society, 20(4), 513-529. https://doi.org/10.1080/136911 8X.2016.1198411

Berger, J., \& Milkman, K. L. (2012). What makes online content viral? Journal of Marketing Research, 49(2), 192-205. https://doi. org/10.1509/jmr.10.0353

Blassnig, S., Ernst, N., Engesser, S., \& Esser, F. (2020). Populism and social media popularity: How populist communication benefits political leaders on Facebook and Twitter. In D. Taras \& R. Davis (Eds.), Power shift? Political leadership and social media (pp. 97-111). New York, NY: Routledge. 
Blassnig, S., \&Wirz, D. S. (2019). Populist and popular: An experiment on the drivers of user reactions to populist posts on Facebook. Social Media+Society, 5(4), 1-12. https://doi. org/10.1177/2056305119890062

Bobba, G. (2019). Social media populism: Features and 'likeability' of Lega Nord communication on Facebook. European Political Science, 18(1), 11-23. https://doi. org/10.1057/s41304-017-0141-8

Brader, T. (2006). Campaigning for hearts and minds: How emotional appeals in political ads work. Studies in communication, media, and public opinion. Chicago, IL: University of Chicago Press.

Brader, T., \& Marcus, G. E. (2013). Emotion and political psychology. In L. Huddy, D. O. Sears, \& J. S. Levy (Eds.), The Oxford Handbook of political psychology (pp. 165-204). New York, NY: Oxford University Press. https://doi.org/10.1093/oxfordhb/9780199760107.013.0006

Carrera, P., Muñoz, D., \& Caballero, A. (2010). Mixed emotional appeals in emotional and danger control processes. Health Communication, 25(8), 726-736. https:// doi.org/10.1080/10410236.2010.521914

Carver, C. S., \& Harmon-Jones, E. (2009). Anger is an approach-related affect: Evidence and implications. Psychological Bulletin, 135(2), 183-204. https://doi.org/10.1037/ a0013965

Chang, C. (2001). The impacts of emotion elicited by print political advertising on candidate evaluation. Media Psychology, 3(2), 91-118. https://doi.org/10.1207/ S1532785XMEP0302_01

Cho, J., Boyle, M. P., Keum, H., Shevy, M. D., McLeod, D. M., Shah, D. V., \& Pan, Z. (2003). Media, terrorism, and emotionality: Emotional differences in media content and public reactions to the September $11^{\text {th }}$ terrorist attacks. Journal of Broadcasting \& Electronic Media, 47(3), 309-327. https:// doi.org/10.1207/s15506878jobem4703_1

Crisp, R. J., Heuston, S., Farr, M. J., \& Turner, R. N. (2007). Seeing red or feeling blue: Differentiated intergroup emotions and ingroup identification in soccer fans. Group Processes \& Intergroup Relations, 10(1), 9-26. https://doi. org/10.1177/1368430207071337
Dang-Xuan, L., Stieglitz, S., Wladarsch, J., \& Neuberger, C. (2013). An investigation of influentials and the role of sentiment in political communication on Twitter during election periods. Information, Communication \& Society, 16(5), 795-825. https:// doi.org/10.1080/1369118X.2013.783608

Davern, M. (2008). Disproportionate allocation to strata. In P. J. Lavrakas (Ed.), Encyclopedia of survey research methods (p. 207). London: Sage Publications. https://doi. org/10.4135/9781412963947

DeSteno, D., Petty, R. E., Rucker, D. D., Wegener, D. T., \& Braverman, J. (2004). Discrete emotions and persuasion: The role of emotion-induced expectancies. Journal of Personality and Social Psychology, 86(1), 43-56. https://doi.org/10.1037/00223514.86.1.43

Doosje, B., Branscombe, N. R., Spears, R., \& Manstead, A. S. R. (1998). Guilty by association: When one's group has a negative history. Journal of Personality and Social Psychology, 75(4), 872-886

Dresner, E., \& Herring, S. C. (2010). Functions of the nonverbal in CMC: Emoticons and illocutionary force. Communication Theory, 20(3), 249-268. https://doi. org/10.1111/j.1468-2885.2010.01362.x

Eberl, J.-M., Tolochko, P., Jost, P., Heidenreich, T., \& Boomgaarden, H. G. (2020). What's in a post? How sentiment and issue salience affect users' emotional reactions on Facebook. Journal of Information Technology \& Politics, 17(1), 48-65. https://doi. org/10.1080/19331681.2019.1710318

Eilders, C. (2006). News factors and news decisions. Theoretical and methodological advances in Germany. Communications, 31(1), 5-24. https://doi.org/10.1515/COMMUN.2006.002

Engesser, S., Fawzi, N., \& Larsson, A. O. (2017). Populist online communication: Introduction to the special issue. Information, Communication \& Society, 20(9), 1279-1292. https://doi.org/10.1080/13691 18X.2017.1328525

Fretwurst, B. (2015). Lotus manual. Reliability and accuracy with SPSS. Retrieved from http://www.iakom.ch/Lotus/LotusManualEng.pdf. 
Frijda, N. H. (1986). The emotions. Studies in emotion and social interaction. Cambridge: Cambridge University Press.

Gardner, W., Mulvey, E. P., \& Shaw, E. C. (1995). Regression analyses of counts and rates: Poisson, overdispersed poisson, and negative binomial models. Psychological Bulletin, 118(3), 392-404. https://doi. org/10.1037/0033-2909.118.3.392

Gross, K., \& D’Ambrosio, L. (2004). Framing emotional response. Political Psychology, 25(1), 1-29. https://doi.org/10.1111/ j.1467-9221.2004.00354.x

Heiss, R., Schmuck, D., \& Matthes, J. (2019). What drives interaction in political actors' Facebook posts? Profile and content predictors of user engagement and political actors' reactions. Information, Communication \& Society, 22(10), 1497-1513. https://doi.org/10.1080/13691 18X.2018.1445273

Hughes, A. (2018). 'Anger' topped 'love' when Facebook users reacted to lawmakers' posts after 2016 election. Retrieved from http://www.pewresearch.org/facttank/2018/07/18/anger-topped-love-facebook-after-2016-election/?amp=1\&_twitter_impression=true.

Jaeger, S. R., \& Ares, G. (2017). Dominant meanings of facial emoji: Insights from Chinese consumers and comparison with meanings from internet resources. Food Quality and Preference, 62, 275-283. https://doi. org/10.1016/j.foodqual.2017.04.009

Jünger, J., \& Keyling, T. (2017). Facepager. An application for generic data retrieval through APIs. Retrieved from https:// github.com/strohne/Facepager.

Keller, T. R., \& Kleinen-von Königslöw, K. (2018). Followers, spread the message! Predicting the success of Swiss politicians on Facebook and Twitter. Social Media + Society, 4(1), 1-11. https://doi. org/10.1177/2056305118765733

Kepplinger, H. M. (2007). Reciprocal effects: Toward a theory of mass media effects on decision makers. The International Journal of Press/Politics, 12(2), 3-23. https://doi. org/10.1177/1081180X07299798

Klinger, U., \& Svensson, J. (2014). The emergence of network media logic in political communication: A theoretical approach. New Media \& So- ciety, 17(8), 1241-1257. https://doi. org/10.1177/1461444814522952

Kühne, R. (2012). Media-induced affects and opinion formation: How related and unrelated affects influence political opinions. Living Reviews in Democracy, 3, 1-20. Retrieved from http://www.cis.ethz.ch/research/living-reviews-in-democracy.html.

Kühne, R., \& Schemer, C. (2015). The emotional effects of news frames on information processing and opinion formation. Communication Research, 42(3), 387-407. https:// doi.org/10.1177/0093650213514599

Larsen, J. T., \& McGraw, A. P. (2014). The case for mixed emotions. Social and Personality Psychology Compass, 8(6), 263-274. https://doi.org/10.1111/spc3.12108

Lazarus, R. S. (1991). Emotion and adaptation. New York, NY: Oxford University Press.

Lazarus, R. S. (2001). Relational meaning and discrete emotions. In K. R. Scherer, A. Schorr, \& T. Johnstone (Eds.), Series in affective science. Appraisal processes in emotion: Theory, methods, research (pp. 37-67). Oxford: Oxford University Press.

Lecheler, S., Schuck, A. R. T., \& Vreese, C. H. de (2013). Dealing with feelings: Positive and negative discrete emotions as mediators of news framing effects. Communications The European Journal of Communication Research, 38(2), 189-209. https://doi. org/10.1515/commun-2013-0011

Lerner, J. S., \& Keltner, D. (2001). Fear, anger, and risk. Journal of Personality and Social Psychology, 81(1), 146-159. https://doi. org/10.1037/0022-3514.81.1.146

Lerner, J. S., \& Tiedens, L. Z. (2006). Portrait of the angry decision maker: How appraisal tendencies shape anger's influence on cognition. Journal of Behavioral Decision Making, 19(2), 115-137. https://doi. org/10.1002/bdm.515

Mackie, D. M., \& Smith, E. R. (2015). Intergroup emotions. In M. Mikulincer, P. R. Shaver, J. F. Dovidio, \& J. A. Simpson (Eds.), APA Handbook of Personality and Social Psychology: Vol. 2: Group Processes (pp. 263-293). Washington, DC: American Psychological Association. https://doi. org/10.1037/14342-010

Marcus, G. E. (2000). Emotions in politics. Annual Review of Political Science, 3(1), 
221-250. https://doi.org/10.1146/annurev. polisci.3.1.221

Micheli, R. (2010). Emotions as objects of argumentative constructions. Argumentation, 24(1), 1-17. https://doi.org/10.1007/ s10503-008-9120-0

Miller, H., Thebault-Spieker, J., Chang, S., Johnson, I., Terveen, L., \& Hecht, B. (2016). "Blissfully Happy" or "Ready to Fight": Varying interpretations of emoji. In Proceedings of the $10^{\text {th }}$ International Conference on Web and Social Media, ICWSM 2016 (pp. 259-268). AAAI press.

Moons, W. G., Leonard, D. J., Mackie, D. M., \& Smith, E. R. (2009). I feel our pain: Antecedents and consequences of emotional self-stereotyping. Journal of Experimental Social Psychology, 45(4), 760-769. https:// doi.org/10.1016/j.jesp.2009.04.016

Myrick, J. G., \& Oliver, M. B. (2015). Laughing and crying: Mixed emotions, compassion, and the effectiveness of a YouTube PSA about skin cancer. Health Communication, 30(8), 820-829. https://doi.org/10.10 80/10410236.2013.845729

Nabi, R. L. (1999). A cognitive-functional model for the effects of discrete negative emotions on information processing, attitude change, and recall. Communication Theory, 9(3), 292-320. https://doi. org/10.1111/j.1468-2885.1999.tb00172.x

Nabi, R. L. (2002). Discrete emotions and persuasion. In J. P. Dillard \& M. Pfau (Eds.), The persuasion handbook: Developments in theory and practice (pp. 289-308). Thousand Oaks, CA: Sage Publications. http:// dx.doi.org/10.4135/9781412976046.n15

Nerb, J., \& Spada, H. (2001). Evaluation of environmental problems: A coherence model of cognition and emotion. Cognition and Emotion, 15(4), 521-551. https://doi. org / 10.1080/02699930126254

Niedenthal, P. M., \& Brauer, M. (2012). Social functionality of human emotion. Annual Review of Psychology, 63, 259-285. https://doi.org/10.1146/annurev. psych.121208.131605

Novak, P. K., Smailović, J., Sluban, B., \& Mozetič, I. (2015). Sentiment of emojis. PloS One, 10(12), 1-22. https://doi. org/10.1371/journal.pone.0144296

Oleszkiewicz, A., Karwowski, M., Pisanski, K., Sorokowski, P., Sobrado, B., \& Sorokows- ka, A. (2017). Who uses emoticons? Data from 86702 Facebook users. Personality and Individual Differences, 119, 289-295. https://doi.org/10.1016/j.paid.2017.07.034

Pavalanathan, U., \& Eisenstein, J. (2015). Emoticons vs. emojis on Twitter: A causal inference approach. Retrieved from http:// arxiv.org/pdf/1510.08480v1

Plantin, C. (2004). On the inseparability of reason and emotion in argumentation. In E. Weigand (Ed.), Emotion in dialogic interaction: Advances in the complex (pp. 269-281). Amsterdam: John Benjamin.

Porten-Cheé, P., Haßler, J., Jost, P., Eilders, C., \& Maurer, M. (2018). Popularity cues in online media: Theoretical and methodological perspectives. Studies in Communication and Media, 7(2), 208-230. https://doi. org/10.5771/2192-4007-2018-2-80

Prada, M., Rodrigues, D. L., Garrido, M. V., Lopes, D., Cavalheiro, B., \& Gaspar, R. (2018). Motives, frequency and attitudes toward emoji and emoticon use. Telematics and Informatics, 35(7), 1925-1934. https://doi.org/10.1016/j.tele.2018.06.005

Redlawsk, D. P. (2006). Feeling politics: New research into emotion and politics. In D. P. Redlawsk (Ed.), Feeling politics: Emotion in political information processing (pp. 1-10). New York, NY: Palgrave Macmillan. https://doi. org/10.1057/9781403983114

Russell, J. A., \& Carroll, J. M. (1999). On the bipolarity of positive and negative affect. Psychological Bulletin, 125(1), 3-30. https://doi.apa.org/doi/10.1037/00332909.125.1.3

Scherer, K. R. (1993). Studying the emotionantecedent appraisal process: An expert system approach. Cognition \& Emotion, 7(3-4), 325-355. https://doi. org/10.1080/02699939308409192

Scherer, K. R. (1998). Analyzing emotion blends. In A. H. Fischer (Ed.), Proceedings of the $10^{\text {th }}$ Conference of the International Society for Research on Emotions (pp. 142148). Würzburg: ISRE.

Scherer, K. R. (2001). Appraisal considered as a process of multilevel sequential checking. In K. R. Scherer, A. Schorr, \& T. Johnstone (Eds.), Series in affective science. Appraisal processes in emotion: Theory, methods, 
research (pp. 92-120). Oxford: Oxford University Press.

Scherer, K. R. (2005). What are emotions? And how can they be measured? Social Science Information, 44(4), 695-729. https://doi. org/10.1177/0539018405058216

Scherer, K. R., \& Tannenbaum, P. H. (1986). Emotional experiences in everyday life: A survey approach. Motivation and Emotion, 10(4), 295-314.

Scherer, K. R., Wallbott, H. G., \& Summerfield, A. B. (Eds.) (2010). European monographs in social psychology. Experiencing emotion: A cross-cultural study. Cambridge: Cambridge University Press.

Smith, C. A., \& Ellsworth, P. C. (1985). Patterns of cognitive appraisal in emotion. Journal of Personality and Social Psychology, 48(4), 813-838.

Smith, E. R., Seger, C. R., \& Mackie, D. M. (2007). Can emotions be truly group level? Evidence regarding four conceptual criteria. Journal of Personality and Social Psychology, 93(3), 431-446. https://doi. org/10.1037/0022-3514.93.3.431

Stieglitz, S., \& Dang-Xuan, L. (2014). Emotions and information diffusion in social media-Sentiment of microblogs and sharing behavior. Journal of Management Information Systems, 29(4), 217-248. https://doi. org/10.2753/MIS0742-1222290408

Tian, Y., Galery, T., Dulcinati, G., Molimpakis, E., \& Sun, C. (2017). Facebook sent- ment: Reactions and Emojis. In L.-W. Ku \& C.-T. Li (Eds.), Proceedings of the Fifth International Workshop on Natural Language Processing for Social Media (pp. 11-16). Stroudsburg, PA: Association for Computational Linguistics. https://doi. org/10.18653/v1/W17-1102

Valentino, N. A., Brader, T., Groenendyk, E. W., Gregorowicz, K., \& Hutchings, V. L. (2011). Election night's alright for fighting: The role of emotions in political participation. The Journal of Politics, 73(1), 156-170. https://doi.org/10.1017/ S0022381610000939

Valentino, N. A., Hutchings, V. L., Banks, A. J., \& Davis, A. K. (2008). Is a worried citizen a good citizen? Emotions, political information seeking, and learning via the internet. Political Psychology, 29(2), 247-273. https://doi.org/10.1111/j.14679221.2008.00625.x

Weber, C. (2012). Emotions, campaigns, and political participation. Political Research Quarterly, 66(2), 414-428. https://doi. org/10.1177/ 1065912912449697

Wirz, D. S. (2018). Persuasion through emotion? An experimental test of the emotion-eliciting nature of populist communication. International Journal of Communication, 12, 1114-1138. 